\title{
Knowledge Discovery in Collaborative Design Projects
}

\author{
Xinghang Dai ${ }^{1}$, Nada Matta ${ }^{1}$, and Guillaume Ducellier ${ }^{2}$ \\ ${ }^{1}$ Tech-cico, University of Technology of Troyes, France \\ \{xinghang. dai, nada.matta\} eutt. fr \\ ${ }^{2}$ LASMIS, University of Technology of Troyes, France \\ \{guillaume.ducellier\}@utt.fr
}

\begin{abstract}
Design projects have evolved to be collaborative, concurrent and multi-disciplinary. Due to these changes, knowledge management for design projects faces new challenges, in order to represent all the elements in a collaborative design project, it is necessary to consider not only decision-making process, but also its context and interaction with other elements.
\end{abstract}

Keywords: Knowledge representation, design project management, classification, project memory.

\section{Introduction}

Design is a collaborative activity, in which several actors with different skills and backgrounds work together to reach a given goal. Design project team is a short-lived organization. Moreover, projects can be done by several companies; actors can belong to different countries (i.e. in big companies). Knowledge is commonly defined by data and information used by an actor in a specific context [1]. Knowledge management aims at enhancing organizational learning in a company based on knowledge produced. It is defined as a cycle of transformation from tacit to explicit knowledge in a company [2]. This type of organizational learning will be based on "knowing how" and "knowing when" [3].

In this paper, we try to face the problem of learning from design project experience. Project memory will be defined at the beginning, and then a knowledge discovery method by classification according to different views of project memory is introduced to extract deep knowledge.

\section{Background}

In design industry, computer-based data process has facilitated information exchange in the whole organization [4], which gives birth to concurrent design. Apart from organizational changes, design teams become multi-disciplinary. Learning from experience can be difficult due to ambiguous interpretation caused by these two elements. We propose a project memory structure to represent collaborative elements in design projects. A project memory describes, "the history of a project and the experience gained during realization of a project" [1]. It must consider mainly project organization, 
reference frames (rules, methods, laws...) used in the various stages of the project, realization of the project, decision-making process.

We need to identify recurrent project events in order to identify routines and strategies related to event context. Strategies can be developed when human, repeating an action in similar context, identify a routine that can be applied to similar situations [7]. We propose in this work to classify collaborative design project traces in order to identify routines and problem solving strategies that help for learning.

\section{Knowledge Discovery by Classification}

\subsection{Knowledge Discovery by Classification}

Low-level data in project memory should be mapped into other forms that might be more compact, more abstract, or more useful [8]. A semantic graph enables knowledge engineers to communicate with domain experts in a comprehensive way [9]. Ontology is a description of shared concepts [10]. In our representation, a semantic network is proposed. Ontological hierarchy of concepts is employed for classification. Classification can be defined as the process in which ideas and objects are recognized, differentiated, and understood, classification algorithms are used in biology, documentation, etc. [11]. Knowledge classification is the process in which knowledge is recognized and reasoned.

\subsection{Knowledge Classification Views of Project Memory}

The goal of project memory is to enhance learning from expertise and past experience [12]. Current representation approaches emphasize on information structuring. The problem is that human can only learn from others by matching to one's own experience, we have to come up with classification models suited within specific context [13]. The traditional knowledge engineering methods ignore completely or partially the mutual influence between context and solution [1], and they show little about the influence of organization. More effort has been done recently to model project memory, we note especially DyPKM. It is a traceability approach developed specifically for project memory[14]. Unfortunately, it is good at knowledge capturing but proposes no solution for knowledge rule extraction. Our method will aim at these problem and classify knowledge in three steps.

Firstly, in order to classify knowledge from different context for different learning intentions, the general semantic network of project memory is decomposed into 4 sub-networks:

- Decision-making process: this part represents the core activity of design project, which helps designers to learn from negotiation and decision-making experience.

- Project organization makes decision: this part represents interaction between organization and decision, which provides an organizational view of decision-making.

- Project organization realizes project: this part represents arrangement of task and project team organization, which focuses learning on project management. 
- Decision-making and project realization: this part represents the mutual influence between decision and project realization, which reveals part of work environment and background.

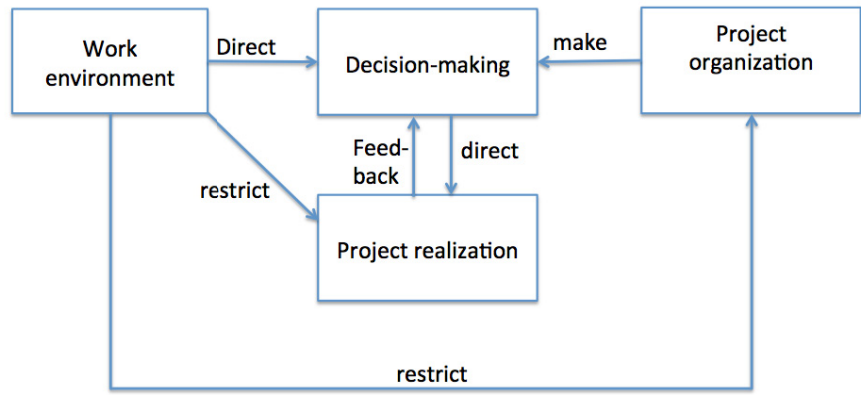

context

Fig. 1. Project memory structure

Secondly, in each sub-network, important concepts are highlighted, and ontological class hierarchy is constructed for classification. Thirdly, machine-learning technique is employed to generate rules between concepts or even networks.

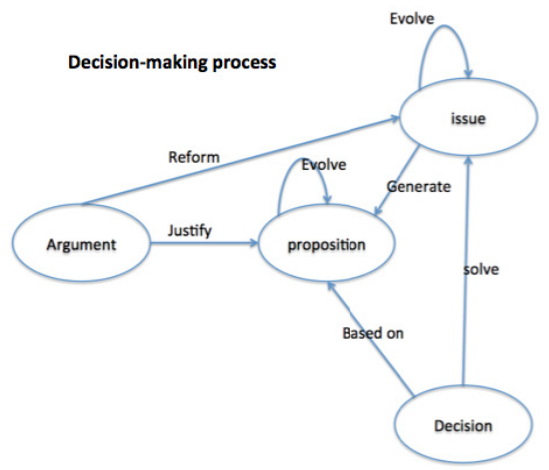

Project realization and decision-making

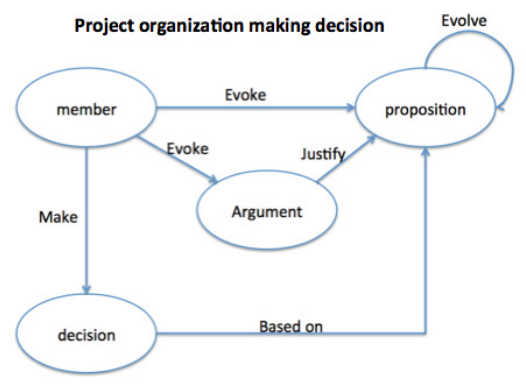

Project organization realizing project
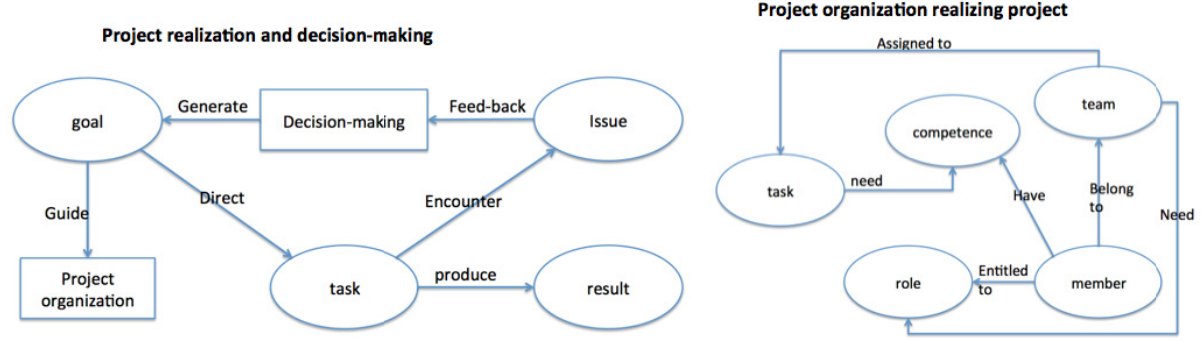

Fig. 2. Sub-networks of project memory 


\section{$4 \quad$ Knowledge Discovery in Project Memory}

\subsection{Sub-network Structure and Class Trees}

1. Decision-making process: Decision-making process represents the most important activity of design projects. Issue is the major question or problem that we need to address, proposition is solution proposed to the issue, and argument evaluates the proposition by supporting or objecting it [5] [6] [15]; Decision is made by selecting the best proposition. Criteria tagging method is proposed to tag each argument with criteria to represent project context, it will be elaborated in our case study.

2. Project organization making decision: The concept "member" is added into the decision-making sub-network to represent the organizational dimension.

3. Project organization realizing a project: This sub-network offers a learning perspective on project realization with an organizational perspective.

4. Decision-making process and project realization: It shows a mutual influence of task arrangement and decision-making process.

\subsection{Knowledge Discovery in Each Sub-network or between Sub-networks}

In order to generate rules that represent interrelations between concepts or sub-networks, machine-learning techniques are considered. One of the most mature and widely used algorithms is classification [16]. An evaluation of major machine learning techniques (statistical methods, decision tree, rule based method and neural network) is carried out in search for the appropriate algorithm [17]-[19]. Our intention is to classify project memory into rule-based knowledge, which leads us to choose a rule-based algorithm ITRULE. It can induce an optimal set of rules from a set of examples [20]. The general rule is taken to be in the form of proposition rules, i.e. if condition A then condition B with probability p.

\subsection{Demonstration of Project Memory Knowledge Discovery}

An example on mechanic design project is illustrated to demonstrate our method. The problem is that the wishbone suspension breaks during test. A decision-making process was initiated in search for a solution. Two propositions were made, arguments on both propositions were presented, and finally one of the propositions was accepted as a decision (Fig. 3). The example is classified into our network in Fig. 4. Decision-making process is traced using memory meetings tools [12]. Project members are assigned to this task. We introduce a predicate member $(r, c)$, where $r$ is role of member and $c$ is competence that member possesses. We have four members: member1 (project manager\&designer, mechanical design), member2 (manufacture technician, mechanical fabrication), member3 (designer, electronic engineering), member4 (market analyst, marketing). 


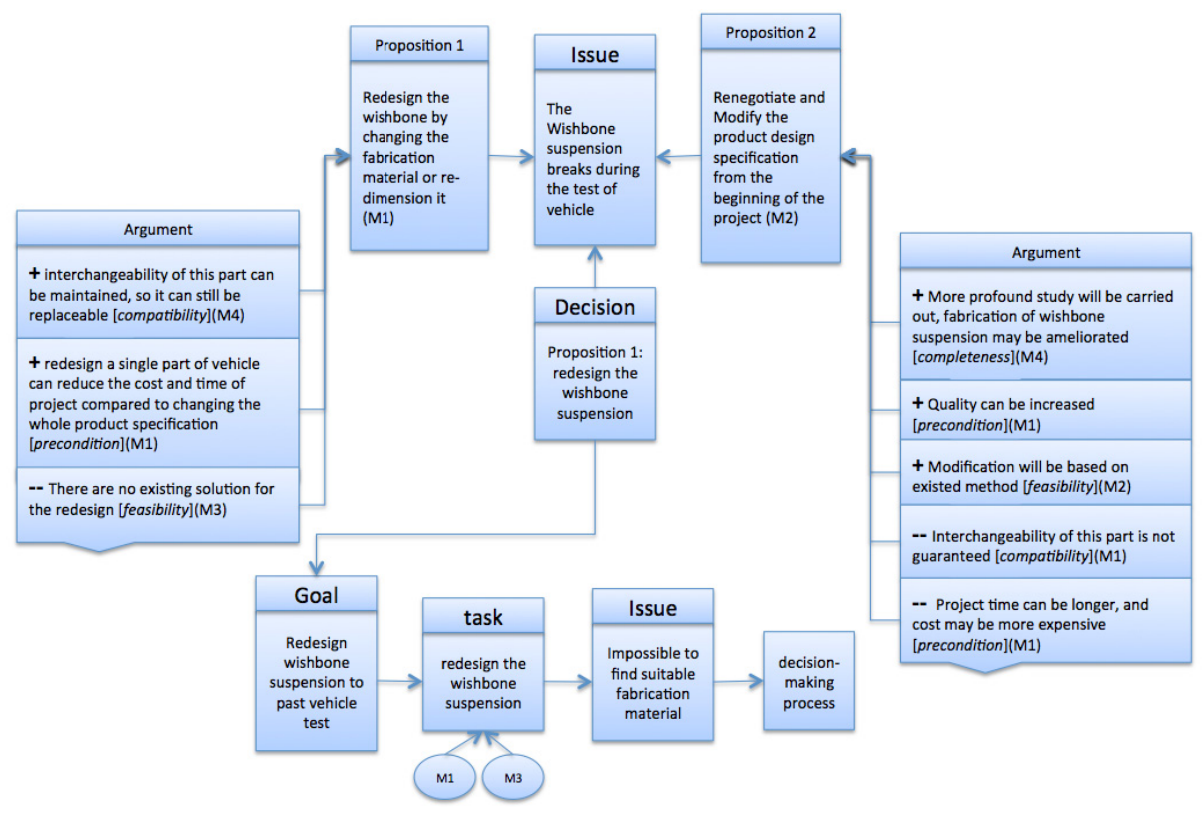

Fig. 3. Structure of the decision-making process "wishbone suspension breaks"

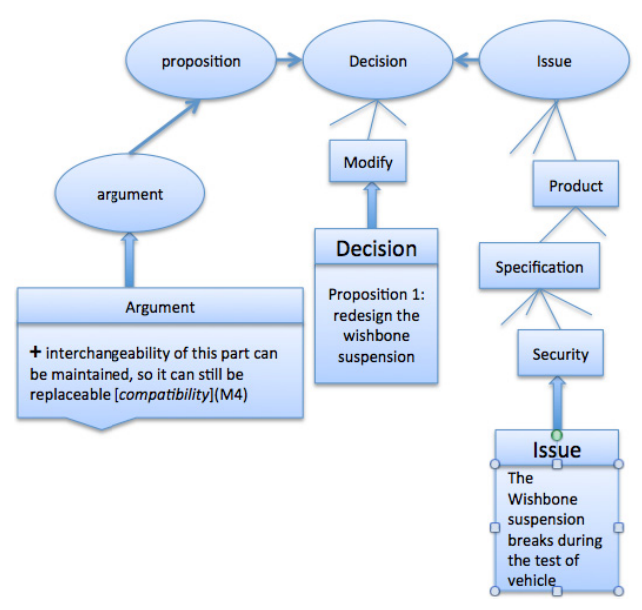

Fig. 4. Classification on issue "wishbone suspension breaks"

From this case we can see that interchangeability of wishbone suspension and project cost are crucial for the decision. However, supposing in another situation where the two elements are not strong enough, the result could be different. Hypothetically, more similar situations occur in a project memory, rules can be generated by the classification of similar graphs. A possible form of rule which can be put in ITRULE as: if issue $\{$ security, wishbone suspension breaks\}, then decision $\{$ modify, redesign the 
wishbone suspension and argument \{compatibility; precondition $\}$ with a possibility of $\mathrm{p}$. This type of graph shows the reason of a solution related to a specific issue in project context. Moreover, solutions can also be influenced by organizational context of a project, for instance: actor's skills, enterprise policy, etc. So more complete knowledge can be discovered by classification between decision-making sub-network and project organization sub-network, or project realization sub-network.

\section{Conclusion and Perspective}

In this paper, we presented a knowledge discovery method in order to enhance learning in organizations. At the beginning, we demonstrated the concept "project memory" in order to introduce a representation structure that is adapted to the new trend of concurrent engineering. Then, a knowledge-oriented classification method is proposed. At last, we showed the sub-networks, and a case study. We showed a technique to extract knowledge rules in project memory by classifying similar routines.

The semantic networks that we gave are based on the traditional knowledge management methods, but we make a connection between different elements in order to give design activities a context with an organizational collaborative dimension. Classification is based on the class trees that we built according to general research on engineering design and project management. The class trees that we proposed in this paper are, what we believe, the most balanced and useful form. In order to apply the classifier, class hierarchy or representation network need to be adapted to a domain.

As we can see the example that we introduced in this paper is an instance demonstration, future test on a larger database will be needed.

\section{References}

1. Matta, N., Ribière, M., Corby, O., Lewkowicz, M., Zacklad, M.: Project Memory in Design, Industrial Knowledge Management - A Micro Level Approach. SPRINGER-VERLAG: RAJKUMAR ROY (2000)

2. Nonaka, I., Takeuchi, H.: The knowledge-Creating Company: How Japanese Companies Create the Dynamics of Innovation. Oxford University Press (1995)

3. Easterby-Smith, M., Lyles, M.A.: Handbook of Organizational Learning and Knowledge Management. Wiley.com (2011)

4. Gerhard, P., Beitz, W.: Engineering Design: a Systematic Approach. Springer, London (1996)

5. Buckingham Shum, S.: Representing Hard-to-Formalise, Contextualised, Multidisciplinary, Organisational Knowledge. In: Proceedings of AAI Spring Symposium on Artificial Intelligence in Knowledge Management, pp. 9-16 (1997), http://ksi.cpsc.ucalgary.ca/AIKM97/AIKM97Proc.htm

6. Conklin, J.E., Begeman, M.L.: IBIS: A Hypertext Tool for exploratory Policy Discussion. ACM Transactions on Office Informations Systems 6, 303-331 (1998)

7. Richard, J.F.: Les activités mentales, Comprendre, raisonner, trouver des solutions. Armand Colin, Paris (1990)

8. Fayyad, U., Piatetsky-Shapiro, G., Smyth, P.: From data mining to knowledge discovery in databases. AI magazine 17(3), 37 (1996) 
9. Sowa, J.: Knowledge representation: logical, philosophical, and computational foundations. Brooks/Cole, Pacific Grove (2000)

10. Gruber, T.: Toward principles for the design of ontologies used for knowledge sharing? International Journal of Human-Computer Studies 43(5), 907-928 (1995)

11. Cohen, H., Lefebvre, C. (eds.): Handbook of categorization in cognitive science, vol. 4(9.1). Elsevier, Amsterdam (2005)

12. Matta, N., Ducellier, G.: An approach to keep track of project knowledge in design. In: Proceeding IC3K/KMIS, 5th International Conference on Knowledge Management and Information Sharing, Vilamoura Algarve, Portugal, September 19-22 (2013)

13. Mai, J.: Classification in context: relativity, reality, and representation. Knowledge Organization 31(1), 39-48 (2004)

14. Bekhti, S., Matta, N.: Project memory: An approach of modelling and reusing the context and the design rationale. Proceedings of IJCAI 3 (2003)

15. Moran, T.P., Carroll, J.M. (eds.): Design rationale: concepts, techniques, and use, Routledge, US (1996)

16. Domingos, P.: A few useful things to know about machine learning. Communications of the ACM 55(10), 78-87 (2012)

17. Michie, D., Spiegelhalter, D.J., Taylor, C.: Machine learning, neural and statistical classification (1994)

18. Dietterich, T.G.: Machine-learning research. AI magazine 18(4), 97 (1997)

19. King, R.D., Cao, F., S.: Statlog: comparison of classification algorithms on large real-world problems. Applied Artificial Intelligence an International Journal 9(3), 289-333 (1995)

20. Smyth, P., Goodman, R.M.: An information theoretic approach to rule induction from databases. IEEE Transactions knowledge and Data Engineering 4(4), 301-316 (1992) 